\title{
COOPERATIVE RESEARCH AND TECHNOLOGY ENHANCEMENT (CREATE) ACT OF 2003
}

\author{
H.R. 2391
}

The Cooperative Research and Technology Enhancement (CREATE) Act of 2003 amends the Patent Act, 35 U.S.C. $\S 103$ (c), to include collaborative researchers affiliated with more than one organization under the "safe harbor" provision of $\S 103(\mathrm{c})$.

In 1984 Congress enacted a series of patent law amendments, including changes to 35 U.S.C $\& 103$, that created a safe harbor against anticipation for inventions that resulted from the joint efforts of researchers by disallowing the sharing of nonpublic information or secret prior art to deny the grant of a patent. In the 1997 case Oddzon Productions, Inc. v. Just Toys, Inc., the Federal Circuit limited the reach of the safe harbor to circumstances where a joint invention was developed by researchers within a single organization. This case produced a situation where an invention that was otherwise patentable might be rendered non-patentable because of the exchange of information between research partners who represented more than one institution. Under this interpretation of $\S 103$, there was no requirement that such information be publicly disclosed or commonly known. The potential chilling effect of the Oddzen holding led to passage of the CREATE Act.

The CREATE Act provides patent protection to inventions that are born from collaborative arrangements between multiple organizations. The Act permits all collaborative researchers to enjoy the same protections from the use of secret prior art as are enjoyed by those who work for a single enterprise by defining the phrase "owned by the same person or subject to an obligation of assignment" to include circumstances in which the parties have entered into a qualifying joint research agreement before making the invention. To gain the benefit of the amended section, the following conditions must be met: 1) the invention and the prior art subject matter must be owned by one or more of the parties to the joint research agreement, and the claimed invention must be made after the date of such agreement; 2) the invention must arise from work performed by or on behalf of the natural or legal persons that are party to the eligible joint research agreement; and 3) the identities of the parties to the joint research agreement must be disclosed in the patent.

This bill applies prospectively only, but includes applications pending at the USPTO on the date of enactment. 